\title{
Experimental Analysis of Heat Affected Zone by Laser Beam Machining
}

\author{
Martin Amar Raj, Ramesh Chandra Panda,Mohammad Israr, Itishree Mohanty
}

\begin{abstract}
LASERstandsforLightAmplification byStimulatedEmission of Radiation. Laser-beam machining is a modern, subtractive, thermal material-removal process that utilizes a high-energy, coherent, high intensity beam of light beam to melxt and vaporize particles on the surface of metallic and non-metallicworkpieces.Laserscanbeusedtocut,drill,weldandmarkandtomake complex job profiles which requires accuracy and precision. Laser also has many medical uses (like in dental industry, surgery, cancertreatment, etc.). This modern technology is finding ways to integrate into daily life with a purpose of easing our work. The main aim of this paper is to study briefly about Laser Beam Machining with parameters included as this paper touches the very key points of working, existence, uses, types and their usage with their respective lifespan.
\end{abstract}

Keywords : Architectural Brass; Excitation; Fibre Laser Beam Machining; HeatAffected Zone (HAZ); Laser Cutting Speed; Kerfwidth

\section{INTRODUCTION}

$\mathrm{T}$ Laser-beam machining is a non-traditional, subtractive, thermal material-removal process that utilizes a high-energy, coherent light beam to melt and vaporize particles on the surface of metallic and non-metallic workpieces. Lasers can be used to cut, drill, weld and mark. LBM is particularly suitable for making accurately placed holes. LBM uses the light energy (focused coherent beam of monochromatic light) to remove material by vaporization and ablation (evaporation or melting of a surface through heating by friction). The light energy is pulsed so that the released energy results in an impulse against the work surface that produces a combination of evaporation and melting with the melted material evacuating the surface at high velocities. Laser beams are being used for a variety of industrial applications, including heat treatment, welding, and measurement as well as cutting, drilling, slitting, slotting, marking operations, scribing. It does not involve mass material removal but does provide rapid material removal with an easily controlled non-contact, non-wearingtool.

\section{LITERATURE REVIEW}

In the year 2003; in the month of March, Giovanni Tani, Luca Tomesani, Giampaola Campana published a paper on "Prediction Of

Revised Manuscript Received on October 30, 2019

* Correspondence Author

Martin Amar Raj, B.Tech 4th year Student, School of Mechanical Engineering, Lingaya'sVidyapeeth,Faridabad, Haryana, India121002.

Mr. Ramesh Chandra Panda, Assistant Professor (Mechanical Engg), Dept. of MechanicalEngg,Synergy Institute of Engineerng \& Technology,Dhenkanal,India

Dr. Mohammad Israr, Professor, Department of Mechanical Engineering, Sur University, Sur - Sultanate of Oman.

Dr.Itishree Mohanty, Principal, Synergy Institute of Engineering \& Technology,Dhenkanal,India

(c) The Authors. Published by Blue Eyes Intelligence Engineering and Sciences Publication (BEIESP). This is an open access article under the CC BY-NC-ND license (http://creativecommons.org/licenses/by-nc-nd/4.0/)
Melt Geometry In Laser Cutting" to find an analytical model for the evaluation of the melt film geometry in laser cutting of steels is developed.In the year 2004; in the month of April, Giovanni Tani, Luca Tomesani, Giampaola Campana, Alessandro Fortunato published a paper on "Quality Factors Assessed By Analytical Modelling In Laser Cutting" to find striation and dross formation are analysed by means of an analytical model which, by considering mass, force and energy balances, evaluates the 3D geometry of the cutting front, and the geometry and temperature fields of the melt film.The machine setup is visualized in fig-1.

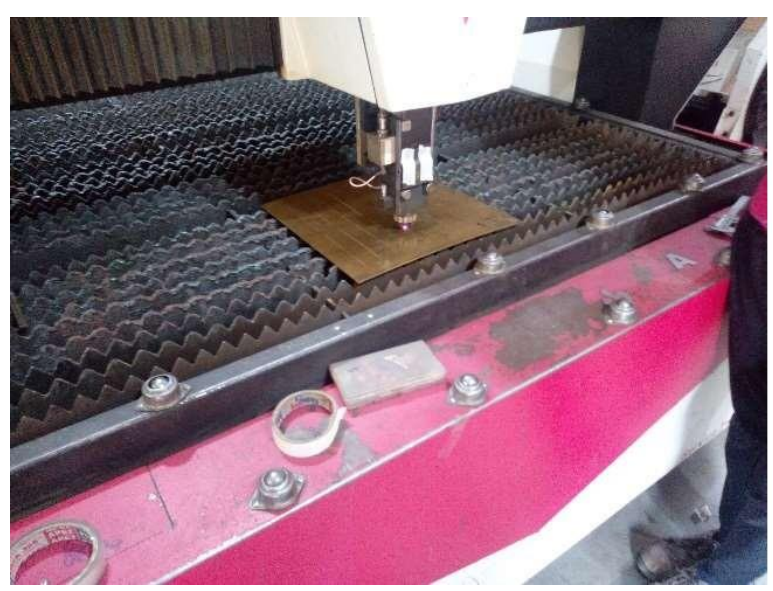

Fg-1- LBM Machine setup

In the year 2006; in the month of January, Miroslav Radovanovic, Predrag DAŠIĆ published a paper on "Research on Surface Roughness by Laser Cut" to find experimental research referring to the determination of surface indicators obtained by laser cutting. The relationships between roughness parameters are given by linear and exponential equations. In the month of January, M. Sobih, P.L. Crouse, and L. Li published a paper on "Laser Cutting Of Variable Thickness Materials Understanding The Problem" to find that Quality of cut was examined in terms of dross attachment, surface roughness, perpendicularity, kerf width, and striation height.

In the year 2007; in the month of September, C.F. Sanchez Valde' sa, C. $\mathrm{Pe}^{\prime}$ rez-Penicheta, C. Nodaa,M. Arronteb, A.J. Batista-Leyvac, Ø. Haugend,.T.H. Johansend, Z. Hane, E. Altshulera published a paper on "Laser Patterning: A New Approach To Measure Local Magneto-Transport Properties In Multifilamentary Superconducting Tapes" to find out that laser patterning of superconducting BSCCO-Ag tapes constitutes a simple approach to measure local transport propertiesin a direct way, even able to separate inter- and intra-filament contributionsto theoverall transportbehaviour of the sample. In the month of November, M. Sobih,

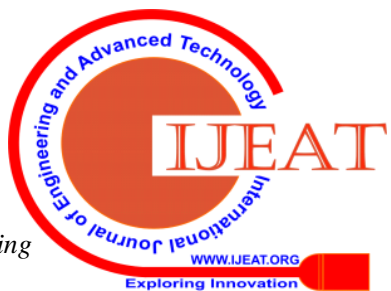




\section{Experimental Analysis of Heat Affected Zone by Laser Beam Machining}

P.L. Crouse, and L. Li published a paper on "Elimination of Striation in Laser Cutting of Mild Steel" to find that High-power laser cutting is extensively used in many industrial applications. An important weakness of this process is the formation of striations (regular lines down the cut surface), which affect the quality of the surfaces produced. The elimination of striation formation is of considerable importance, since it could open up a variety of novel high-precision applications. In the year2008;inthemonthofNovember,

Mohd Aiman Shah Bin Abdullah published a paper on "Carbon Dioxide $\left(\mathrm{CO}_{2}\right)$ Laser Cut Quality Of Acrylic With Different Power Levels" to find and examine the effects of laser cutting of acrylic material with the use of different power levels and constant feed rate.In the year 2009; in the month of October, I.V. Shubapublishedapaperon "Mechanical Impact Of Gas Flow On The Surface Of Penetration Channel Walls In Gas-Laser Cutting"tofindoutthefeatures ofassistgasflowingas-lasercuttingof10mm steel plates. In the year 2010; in the month of October, JESS PAYNE published a paper on "Cutting Through The Surface: The Use Of Laser Cutting Technology With Traditional TextileProcess" to find out the use of laser cutting technology in conjunction with textile materials, but little research has been conducted into the use of this technology in conjunction with textileprocesses.

In the year 2010; in the month of October, JESS PAYNE published a paper on "Cutting Through The Surface: The Use Of Laser Cutting Technology With Traditional Textile Process" to find out the use of laser cutting technology in conjunction with textile materials, but little research has been conducted into the use of this technology in conjunction withtextileprocesses.

In the year 2011; in the month of April, Miroslav Radovanovic, Milos Madic published a paper on "Experimental Investigations Of $\mathrm{CO}_{2}$ Laser Cut Quality: A Review" to find out the state of the art in the field of $\mathrm{CO}_{2}$ laser cutting of various engineering materials with special emphasis on experimental investigations that dealt with analysing process parameters that affect the cut quality characteristics. In the month of June, Arun Kumar Pandey and Avanish Kumar Dubey published a paper on "Intelligent Modelling of Laser Cutting of Thin Sheet"tofindouta modellingstudyoflasercutting process of a thin metal sheet.

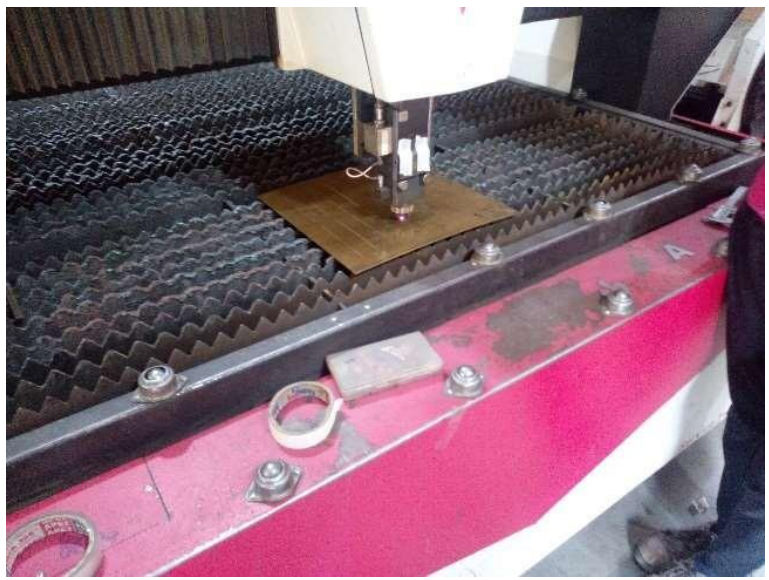

Figure(1): A Picture of a Fibre Laser Beam Machine working on Architectural Brass Plate.

In the year 2012; in the month of May, M. Sobih and W.M. Hussein published a paper on "Scoring Model For Fibre Laser Cutting Of Mild Steel Sheets" to find out the use of a scoring model of Projection to Latent Structure (PLS) technique and applies it to study the effects of fibre laser cutting process parameters and their interactions on the quality achieved during cutting mild steel sheets. In the month of August, Pradipkumar S.Chaudhari, Prof. Dhaval M. Patel published a paper on "Parametric Effect Of Fibre Laser Cutting On Surface Roughness In 5 Mm Thick Mild Steel Sheet (IS-2062)" to aim at evaluating steel is a daily used material and dominantly processing parameters, such as the laserusedinthelasercuttingindustry. Inthemonthof August, Y.Nukman, M. A. Hassan and M. Z. Harizam published a paper on "Optimization Of Prediction Error In $\mathrm{CO}_{2}$ Laser Cutting Process By Taguchi Artificial Neural Network Hybrid With Genetic Algorithm" to find out Simulation and prediction of $\mathrm{CO}_{2}$ laser cutting of Perspex glass has been done by feed forward back propagation Artificial Neural Network (ANN). In the month of September, I. A. Choudury,

\section{W.C. Chong, G. Vahid published a paper on "Hole}

Qualities In Laser Trepanning Of Polymeric Materials" to find out the materialremovalprocess isbyfocusinglaserbeamontotheworkmaterialfor melting and vaporizing the unwanted material to create a hole.In the year 2013; in the month of November, Mustafa Zaidi, Imran Amin, Ahmad Hussain, Nukman Yusoff published a paper on "Estimation Of Ann Modelling Of Laser Cutting With Missing Values" to find out Orthogonal array based experimental data were trained by Artificial Neural Network (ANN) for the modelling of laser cutting process of Perspex sheet.

In the year 2014; in the month of February, Majid Hashemzadeh published a paper on "Investigations Into Fibre Laser Cutting" to find out a better study fibre oxygen/nitrogen laser cutting of mild steel, in terms of kerf width, heat affected zone, surface roughness and the phenomenon of striation generation. Better understanding of laser piercing is needed to be able to minimise the amount of material wastage in laser cutting. In the month of April, B.Moharana, Rakesh Gupta, Bashishth Kumar Kushwaha published a paper on "Optimization And Design Of A Laser-Cutting Machine UsingDelta Robot" to find out a particular Delta, developed for high-speed laser cutting. In the month of May, M. Meboldt, Q. Lohmeyer and B. Leutenecker published a paper on "Prototyping With Laser Cutters In Large Engineering Design Classes" to find out an educational approach that introduces laser cutters for application in large engineering design classes to cost-efficiently realize high-fidelity prototypes and thus, allow several hundred students to early experience the interdependencies of their technical system's design and its functionality in manufacture, assembly and operation. In the month of June, V. Senthilkumar published a paper on "Laser Cutting Process - A Review" to find out a state of the art in the field of laser cutting process. In the month of November, K.F. Tamrin, Y. Nukman, I.A. Choudhury, S. Shirley published a paper on "Multiple-Objective Optimization In Precision Laser Cutting Of Different Thermoplastics" to find out the use of grey relational analysis to determine a single optimized set of cutting parameters for three different thermoplastics. In the year 2015; in the month of February, Chithirai Pon Selvan M, Nethri Rammohan and Sachidananda HK published a paper on "Laser Beam Machining: A Literature Review On Heat Affected Zones, Cut Quality And Comparative Study" to find out that affect the quality of the process such as heat affected zone formed in the work-piece, laser cut quality and why laser beam machining is more advanced than the other machining processes.

\section{Published By:}


In the month of March, Archana Tamrakar, S. N. Siddique published a paper on "Optimization of Hybrid Robot for Laser Cutting Operations" to find out a study of combinations of parallel and serial manipulator developed for high-speed laser cutting.

In the month of April, Dustin Beyer, Serafima Gurevich, Stefanie Mueller, Hsiang-Ting Chen, Patrick Baudisch published a paper on "Platener: Low-Fidelity Fabrication Of 3D Objects By Substituting 3d Print With Laser-Cut Plates" to find out a system that allows quickly fabricating intermediate design iterations of 3D models, a process also known as low-fidelity fabrication. In the month of May, Dongyun Wang, Qiwei Yu, Yu Zhang published a paper on "Research on Laser Marking Speed Optimization by Using Genetic Algorithm" to find out to help improve the laser's travel efficiency to some extent. NiniLi4 extracted the nodes from the contour, then optimized the path nodes using a local search optimization algorithm, and eventually obtained an approximate optimal solution. To further improve laser marking efficiency, a new method based on GA is proposed. In the month of June, Yogesh D. Pawar, Dr. K. H. Inamdar published a paper on "Optimisation Of Quality Characteristics OfLaserCutting" andthemain aim of this paper is to evaluate above mentioned quality characteristics by varying different input parameters such as laser power, speed, feed, pulsing frequency, gas pressure, duty etc. In the Sheet Metal Parts" to find out optimization problem for NC laser combined cutting of sheet metal parts was taken as the research object in this paper. The problem included two contents: combined packing optimization and combined cuttingpathoptimization.

In the year 2018; in the month of January, P. Jamaleswara Kumar, A. Siva Sai Tarun, M. Gowtham, P. Thamma Rao, G. Yashwanth published a paper on "Design And Fabrication Of Portable Laser Cutting And Engraving Machine" to find out the fundamental goal is to design and fabricate the laser cutting and engraving machine which is convenient to controlled by the Arduino CNC. In the month of April, Kishore Shelke, Swapnil Maindargi, Akshay Vetal, Pranav Mantri, Amit Nichat published a paper on "Application Of Reverse Engineering For Converting Cartesian Coordinate System Into Laser Cutting Machine" to find out the application of reverse engineering for converting Cartesian coordinate system into laser cutter. In the month of June, J. Sebastian Joyal, R. Ram Kumar, K. Ganesh, I. Justin Antony Raj published a paper on "Experimental Investigation On Laser Cutting Of Aluminium Alloy (BS1100) Sheet Using CO2 Laser" to find out the laser cutting operation on aluminium alloy using CO2 laser was carried out by considering the process parameter laser power, cutting speed, nozzle standoff distance and assist gas pressure. In the month of June, Sandeep Kumar Singh and Ajay Kumar Maurya published a paper on "Review on Laser Beam Machining Process Parameter Optimization" to find out that depending on the application of the laser cutter a selection of different gases are used in conjunction with the cutting.

\section{DESCRIPTION OF FIBRE LASER MACHINE}

Laser cutting has become one of the most reliable advanced manufacturing technologies for industrial productions. Laser cutting is a non-contact process so there is no force mechanically applied to the workpiece except for that from the pressure of the assistant gas. Therefore, strong clamping fixtures are not necessary and hence, thin or delicate sheets can be cut without any mechanical damage. Fibre lasers are solid-state lasers using glass fibres as an active medium. Fibre laser cutting works by focusing the power of a high-power laser onto the surface of the material to be cut. The energy in the laser beam is absorbed into the surface of material, and the energy of the laser is converted into heat, which melts or vaporizes the material. Additionally, gas is focused or blown into the cutting region to expel or blow away the molten metal and vapour from the cutting path. Because of their robust construction and the high degree of utilization of the supplied energy, fibre lasers are suitable for many different applications.

1. Working Principle:

Key principle behind the operation of LASER was first published in 1917 by Albert Einstein when he hypothesized that under the proper conditions light energy of a particular frequency could be used to stimulate the electrons in an atom to emit additional light exactly withthesame characteristics as the original stimulating lightsource.

\section{Merits:}

Highoutputpoweroflaserbeamformachining.

High opticalquality.

Compact size.

Higher reliability.

Low installationcost.

Minimal maintenance.

Higher productivity.

Effective marking and engraving.

Ability to perform so many different processes (like same laser machine can be reprogrammed for Laser marking, Laser welding, Laser drilling, Laser engraving, Laser ablation, Additivemanufacturingand,Lasercleaning).

\section{Demerits:}

Major Drawbackisthatmost of the coretechnology of fibre laser is in the hands of foreign mature companies, so some components of fibre laser cutting machine are imported that increase the machine cost, so generally fibre laser cutting machine price is expensive. Also when cutting thick material or high reflective material, the cutting speed is veryslow.

\section{Uses:}

Material processing (marking, engraving, cutting).

All known Manufacturing Processes (like Shipbuilding, Welding, Drilling, Electronics, etc.).

Telecommunications.

Spectroscopy.

Medicinal Industry (Cosmetic Surgery, Hair Removal, Cancer Treatment).

Marking components for traceability (like VIN numbers, ID plaques, etc.).

\section{General Working:}

First, a part program is written or a drawing is upload on the Laser Beam system containing all necessary details about the job to be performed. This drawing is also checked for any type of errors.

Second, laser material is filled into laser discharge tube.

Third, power is switched on, which is connected to flash lamp and it excites electrons of atoms.

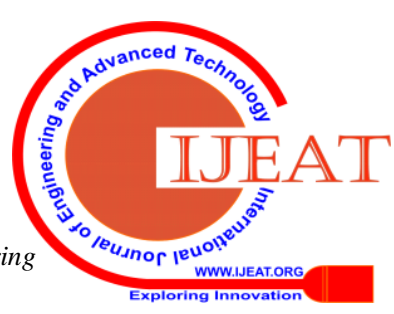




\section{Experimental Analysis of Heat Affected Zone by Laser Beam Machining}

- The atoms absorbs light energy produced by flash lamp. This causes electrons tojump from lower to higher excitation level. This makes atom unstable.

- When atoms absorb sufficient energy, it starts emit it continuously. This produces highly amplified, same frequency, and same wavelength coherentlight.

This laser light is collected by the focus lens and is directed toward the work piece.

6. Purpose of Experiment:

The aim of the project was to determine the cutting effects (mainly Heat Affected Zone) of a Fibre LASER Beam Machine which uses gas for cutting aid and flushing (O2) on the Architectural Brass by varying some working parameters (mainly cutting speed) and to record observations attained physically.

Thickness of Plates: $1 \mathrm{~mm}$. The dimensions oftheplateareasfollows: (14 x 14 inch) or (355.6 x $355.6 \mathrm{~mm})$.

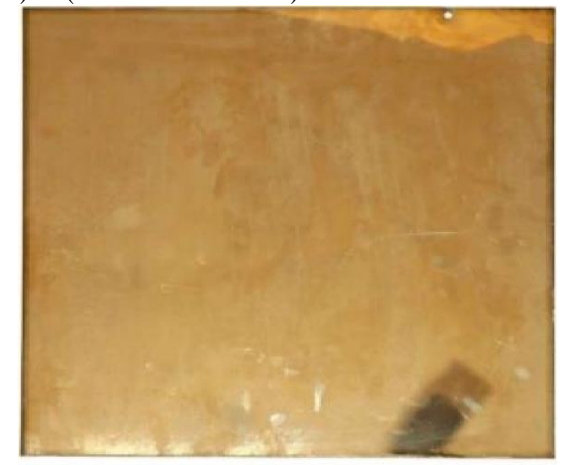

Figure (3): A Picture of an Architectural Brass Plate (Brass C38500).

\begin{tabular}{|c|c|c|}
\hline \multicolumn{3}{|c|}{$\begin{array}{l}\text { Architectural Brass (Gold Finish) (Brass C38500) } \\
\text { Properties }\end{array}$} \\
\hline $\begin{array}{l}\text { Applicat } \\
\text { ion }\end{array}$ & 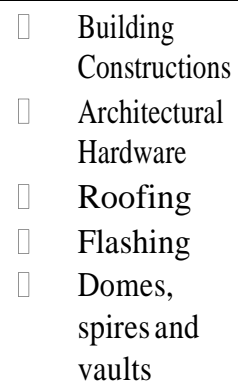 & $\begin{array}{cl}\square & \text { Wall cladding } \\
\square & \text { Building expansion joints } \\
\square & \text { Indoor design } \\
\square & \text { Green buildings } \\
\square & \text { Used inFinishes }\end{array}$ \\
\hline $\begin{array}{l}\text { Mecha } \\
\text { nical } \\
\text { Prope } \\
\text { rties }\end{array}$ & $\begin{array}{ll}\square & \text { Density }=84 \\
\square & \text { Hardness (Rc } \\
\square & \text { Tensile Stren } \\
\square & \text { Yield Streng } \\
\square & \text { Elongation at } \\
\square & \text { Machinabilit } \\
\square & \text { Shear Modul } \\
\square & \text { Shear Streng } \\
\square & \text { Poisson's Ra } \\
\square & \text { Elastic Modu }\end{array}$ & $\begin{array}{l}0 \mathrm{~kg} / \mathrm{m}^{3} \\
\mathrm{kwell}, \mathrm{B})(\mathrm{M} 30 \text { temper})=65 \\
\text { th }=415 \mathrm{MPa} \\
\mathrm{h}=140 \mathrm{MPa} \\
\text { reak (in } 50 \mathrm{~mm}, \mathrm{M} 30 \text { temper })=30 \% \\
=90 \\
\mathrm{~s}=37 \mathrm{GPa} \\
\text { (M30 temper) }=240 \mathrm{MPa} \\
\mathrm{lo}=0.34 \\
\mathrm{us}=117 \mathrm{GPa}\end{array}$ \\
\hline
\end{tabular}

\begin{tabular}{|l|ll|}
\hline Thermal & $\square$ & Thermal Expansion Coefficient $=20.9 \mu \mathrm{m} / \mathrm{m}^{0} \mathrm{C}$ \\
Properties & $\square \quad$ Thermal Conductivity $=123 \mathrm{~W} / \mathrm{mK}$ \\
& $\square \quad$ Poor Cold Working \\
& $\square \quad \begin{array}{l}\text { Excellent Hot Working } \\
\text { Only Brazing and Soldering useful }\end{array}$ \\
\hline $\begin{array}{l}\text { Electrical } \\
\text { Properties }\end{array}$ & $\square \quad$ Electrical Relative Conductivity $=394 \mathrm{~S} / \mathrm{m}$ \\
\hline Heat & $\square \quad$ Annealing at $\left(427-593^{\mathrm{O}} \mathrm{C}\right)$ \\
Treatment & $\square \quad$ Forging at $\left(621-732^{\mathrm{O}} \mathrm{C}\right)$ \\
\hline Demerits & $\square \quad$ Not useful for welding process \\
\hline Price & $\begin{array}{l}\text { Inherit all brassdrawbacks } \\
\text { Price varies as per the thickness of sheet and the size of } \\
\text { the sheet purchased. }\end{array}$ \\
\hline Compositi & $\square \quad \begin{array}{l}\text { Copper }=57 \% \\
\text { on }\end{array}$ & $\begin{array}{l}\text { Zinc }=40 \% \\
\text { Lead }=3 \%\end{array}$ \\
\hline Need & $\begin{array}{l}\text { Tomakebuildingconstructioncheaper,moredurable,havinglonglifespan } \\
\text { withless } \\
\text { carbon footprints. }\end{array}$ \\
\hline
\end{tabular}

Table (1): A Table depicting necessary details about Architectural Brass.

Figure (4.1,4.2,4.3): Pictures depicting the microstructures of Architectural Brass.

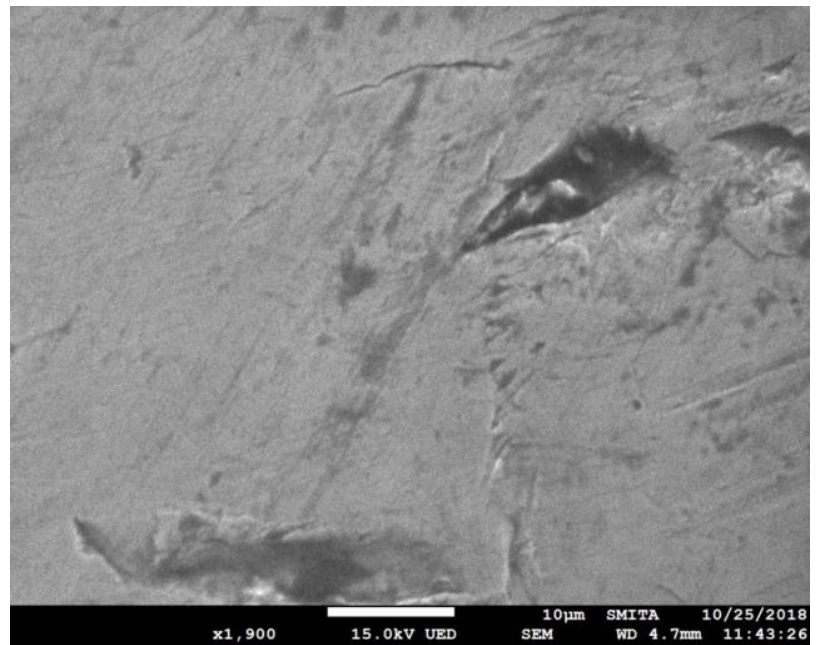

Figure (4.1): Pictures depicting the microstructures of Architectural Brass.

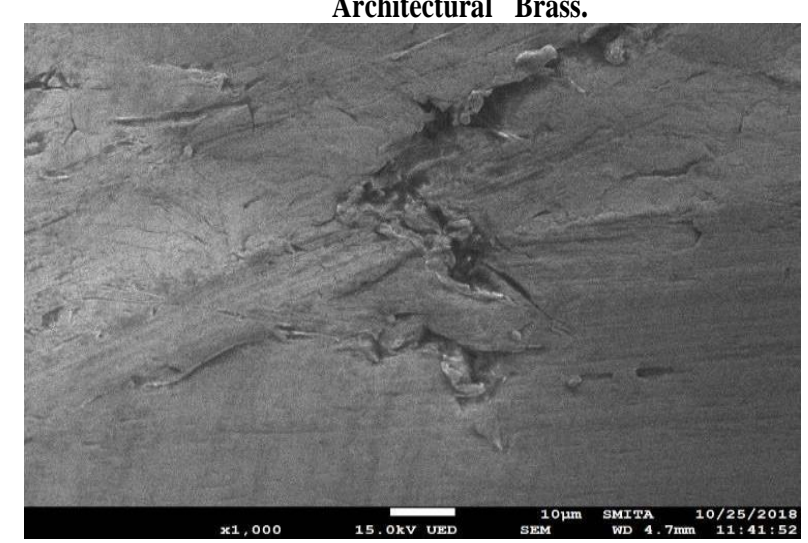

Figure (4.2): Pictures depicting the microstructures of Architectural Brass. 


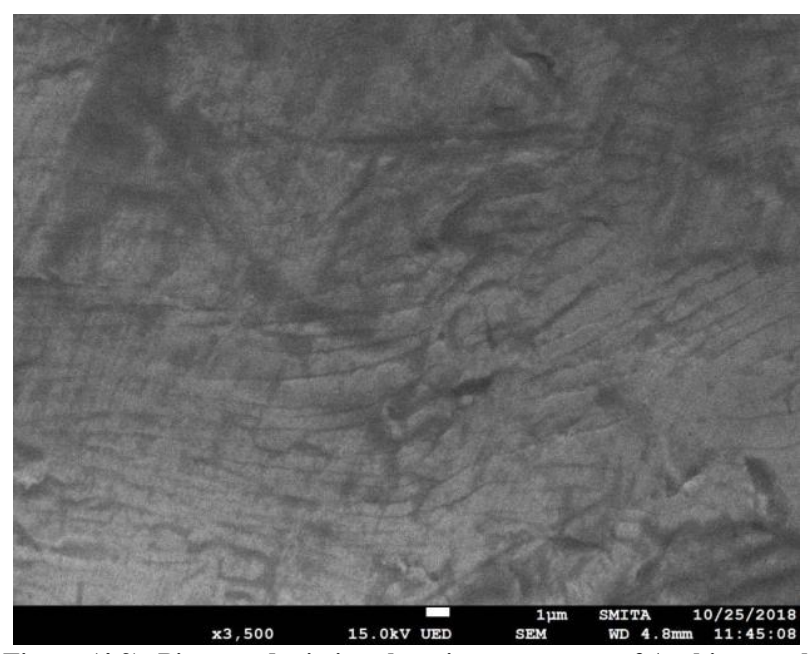

Figure (4.3): Pictures depicting the microstructures of Architectural Brass.

\section{Machine used for Experiment:}

A 1000W Fibre LASER Beam Machine was used in this experiment to machine Architectural Brass (Brass C38500) with varying cutting speed ranging from $00 \mathrm{~mm} / \mathrm{sec}$ to $100 \mathrm{~mm} / \mathrm{sec}$, with oxygen gas used for cutting aid and flushing. Detailed specifications ofthismachineare asfollows:

1) Name of the Machine:

CypCut Laser Cutting System GF-1530T.

Description: Ideal solution for variable products, applied for both round, square tube and plate metal sheet cutting etc. Super dynamic performance, high efficiency \& quality, Low running electrical and gas cost, CNC Laser software controlling system utilised hereis“"CypcutLaserCuttingSystem”.

MaximumOperating PowerCapacity: 1000W.

Max Cutting thickness: Carbon steel (12mm), Stainless steel (6mm) Aluminium (4mm), Copper (3mm), Brass (3mm).

2) Machine Technical Parameters:

Operating Laser power Capacity: 500W, 700W1000W.

Lasermaterialsource:GermanyIPGfibrelaser resonator.

Laser source:

N-light / IPG fibre laser resonator.

Processing surface / Working Table: 3000mm x

$1500 \mathrm{~mm}(\mathrm{LxW})$.

Pipe / Tube processing $(\mathrm{L} \times \Phi)$ :

L3000mm, $\quad \Phi 20-200 \mathrm{~mm} \quad(\Phi 20-300 \mathrm{~mm}$ for option).

CNCcontrol:ShanghaiFISCUTCypCut.

Laser head Manufacturer: Switzerland based Raytools with Auto-Focus feature.

$\begin{array}{ll}\text { Operating } & \text { Power supply: AC380V } \\ & \pm 5 \% 50 / 60 \mathrm{~Hz} \text { (3phase). }\end{array}$

Total electric power: $17 \mathrm{KW}$.

Maximum position speed of $X$ and $Y$ axle: $72 \mathrm{~m} / \mathrm{min}$.

AccelerationofLaserBeam(duetogravity): $1 \mathrm{~g}$.

Max load of working table: $1000 \mathrm{~kg}$.

Drawing programming mode: AI, DWG, PLT, DXF, PDF, PRT, DST, DXF, NV format

drawings are import directly.
Machine weight:5.3Tons(1Ton=1000kg).

Tube Diameter: $20 \mathrm{~mm}$ (minimum) to $200 \mathrm{~mm}$ (maximum).

Cooling System: Water Chiller.

Lubrication System: Automatic Lubrication system.

Assist Gas Choosing Control: Oxygen (O2), Carbon

Dioxide (CO2) \& Nitrogen (N2) are used. In this setup,

Oxygen $(\mathrm{O} 2)$ is employed.

Nozzle Diameter $(\phi)$ (in mm): 1.

Laser Positioning System: Gear Rack (Germany Atlanta

Co.)\&Linear(RoxrothCo.).

Electrical Servo Motor Provider: Yaskawa Co.(Japan).

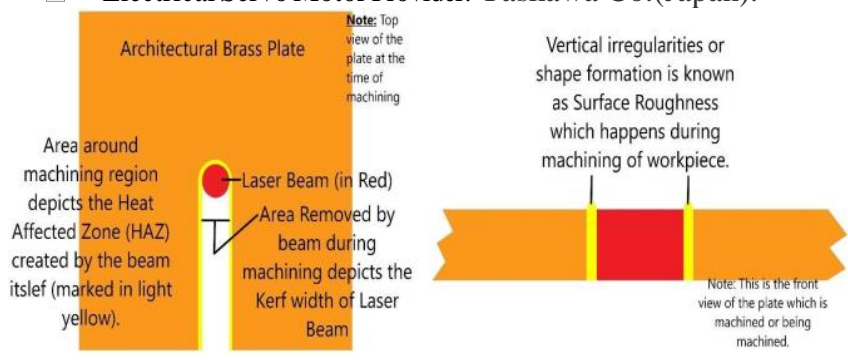

Figure (5): A typical sketch depicting LASER beam working output parameters.

3) Machine Working Parameters:

A. Basic Parameter (1):

Cut Speed: Fixes the actual speed of cutting. There is acceleration and deceleration at the first and last sections of cutting as well as the corners of cutting sections. The actual cutting speedis oftenless than the setspeed.

- LiftHeight:Settheliftheight oflaserheadafter cutting asegment of drawing. Vertical axis will lift to a certain height after suspendingcutting, and this is known as lift height.

B. Cutting mode (2):

Standard: Cutting as per set parameters.

Fixed Height Cut: In this, laser head is fixed at a certain height.

Extra-Plate Follow: During cutting, portion of the laser head staying outside the plate will stay at the "Reference height", and will start cutting after detecting the board, commonly is used for cutting metalplate.

C. Piercing mode (3):

Direct Cutting: It is commonly used for thin board cutting, withthicknesslessthan $5 \mathrm{~mm}$.

$\square$ Two Stage Piercing: It is commonly used for thick board cutting with thickness rangingfrom $5 \mathrm{~mm}$ to $9 \mathrm{~mm}$.

$\square$ Three Stage Piercing: It is based on stage piercing. You can choose whether needs progressive piercing or not. And this method is commonly used for thick board cutting with thicknessranging from $9 \mathrm{~mm}$ to $13 \mathrm{~mm}$.

D. Cutting Parameters (4):

$\square$ Cutting Height:Itfixes theheight of laserhead with respect to the board during cutting operation.

$\square$ Cutting Gas: Defines the auxiliary gas used in cutting operation.

Published By: 


\section{Experimental Analysis of Heat Affected Zone by Laser Beam Machining}

Cutting Pressure: Defines the pressure of auxiliary gas during cutting operation.

$\square$ PeakCurrent/CutCurrent:Set thepeak current of fibre laser. Peak power fixes the maximum cutting power that a machine can reachduring machining.

Cutting Power: Set the laser power used during cutting operation.

Cutting Frequency: Defines the carrier frequency of PWM modulation signal during cutting operation.

Cut Focus: The position of focus far from cutting head nozzle.

Piercing Time: The time needed to make cutting more fully.

Laser Off Delay: Delay period for ensuring complete cuttingbeforethelaseristurnedoff.

$\square$ Piercing Speed: Defines the speed from piercing height slow down to the cutting height during progressive piercing only.

ExtraPuffing: Settimeforthelasertoremain laser off after piercing, in order to make the plate cool, ready for another cutting operation if any.

E. Other parameters (5):

Uncut:Thecutsection whichisnotprocessed.

$\square$ Unfollow: Height controller does not follow motion of cutting head over any cutting section during cutting.

$\square$ Keep Puffing: Keep puffing during cutting operation.

$\square$ Short Move Unlift: After select this option, if the move distance between two graphical cut section is less than the value of "Unlift move distance" set in global parameter, then Vertical axis remains fixed and directly moves to the beginning point of the next graphics to start processingnewsectionwithoutstopping.

$\square$ Pre-piercing: Before actual cutting, piercing in advance at thebeginningpoint of graphics(or lead startingpoint).

$\square$ Cut with Film: You can use film parameter to perform one time cut along the cutting path, and then the normal processing according to the cutting layerparameters.

F. $\quad \square$ PathCool:Thisfeatureallowsthemachineto scan along the original track regarding cooldown time period, in order to accelerate parts rapid cooling and reduce the impact of thermal expansion as well as contractioneffect on the accuracy of the work-piece. Slow start (6):

$\square \quad$ Start length: Enable slow start, to prevent cut thick plate without completing at the beginning.

$\square \quad$ Start speed:Defines the speed of slowstart.

G. Dynamic Power and Frequency Adjustment (7):

After selecting "Dynamic Power Adjustment" option and "Dynamic Frequency Adjustment" option,thiswillhelpusto set the cutting power and frequency with respect to the change in speed during the cutting process, and the specific changes are determined by the power and frequency curve. You can select "Curve Edit" button to edit power and frequency curve as per you will.

A. Figure (6): A Picture of a Control Panel of CypCut Laser Cutting System GF-1530T with all operational parameters, along with cutting methods.

Observations drawn from Experiment:

While conducting the experiment and observing the results collected andrecordedaregivenbelow:

Kerf Width (KW) decreases as we increase the laser cutting speed from minimum to maximum.

Surface Roughness (SR) decreases as the speed increases.

Dimensional Accuracy (DA) of laser cut increases as we rise the cutting speed due to the reason that Kerf Width and Surface Roughness had lowered down.

Observations are drawn on the recordings based on cutting speed when speed is:o $10 \mathrm{~mm} / \mathrm{sec}$ :

\section{OBSERVATION}

Readings with variable parameter is depicted below in table 2

\begin{tabular}{|c|c|c|c|c|}
\hline S/No. & $\begin{array}{l}\text { Cutting } \\
\text { Speed }\end{array}$ & $\begin{array}{l}\text { Cut } \\
\text { Pressure }\end{array}$ & $\begin{array}{l}\text { Piercing } \\
\text { Time }\end{array}$ & $\begin{array}{l}\text { Cut } \\
\text { Height }\end{array}$ \\
\hline 1 & $\begin{array}{l}10 \\
\mathrm{~mm} / \mathrm{sec}\end{array}$ & 10 bar & $200 \mathrm{~mm}$ & $15 \mathrm{~mm}$ \\
\hline 2 & $\begin{array}{l}30 \\
\mathrm{~mm} / \mathrm{sec}\end{array}$ & 10 bar & $200 \mathrm{~mm}$ & $15 \mathrm{~mm}$ \\
\hline 3 & $\begin{array}{l}40 \\
\mathrm{~mm} / \mathrm{sec}\end{array}$ & 10 bar & $200 \mathrm{~mm}$ & $15 \mathrm{~mm}$ \\
\hline 4 & $\begin{array}{l}50 \\
\mathrm{~mm} / \mathrm{sec}\end{array}$ & 10 bar & $200 \mathrm{~mm}$ & $15 \mathrm{~mm}$ \\
\hline 5 & $\begin{array}{l}60 \\
\mathrm{~mm} / \mathrm{sec}\end{array}$ & $10 \mathrm{bar}$ & $200 \mathrm{~mm}$ & $15 \mathrm{~mm}$ \\
\hline 6 & $\begin{array}{l}70 \\
\mathrm{~mm} / \mathrm{sec}\end{array}$ & 10 bar & $200 \mathrm{~mm}$ & $15 \mathrm{~mm}$ \\
\hline 7 & $\begin{array}{l}80 \\
\mathrm{~mm} / \mathrm{sec}\end{array}$ & $10 \mathrm{bar}$ & $200 \mathrm{~mm}$ & $15 \mathrm{~mm}$ \\
\hline
\end{tabular}

Laser Cuts made in an Architectural Brass Plate with varying laser cutting speed

Operating Parameters of the machine at the time of cutting:

Cutting Mode: Direct Cutting Mode.

Cut Speed (mm/sec): 10, 30, 40, 50, 60, 70 and 80.

Lift Height (mm): 15.

Cut Height (mm): 0.7.

Cut Gas: Air (Oxygen).

Cut Pressure (Bar): 10.

Operating Laser Power: $1000 \mathrm{~W}$ or $1 \mathrm{~kW}$.

Cut Current / Peak Current

Published By:

Blue Eyes Intelligence Engineering

\& Sciences Publication

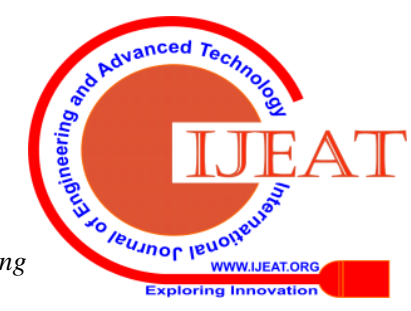


(\%): 100.

Cut Frequency (\%): 100.

Piercing Time (ms): 200.

Laser Off Delay (ms): 0.

Flushing Gas: Oxygen.

Nozzle Focus: $2 \mathrm{~mm}$.

Nozzle Diameter: $1 \mathrm{~mm}$.

Keep Puffing ison.

Short Move Uplift is on.

Observations concluded from experiment:

While conducting experiment, following things were observed:

\section{CONCLUSION}

It has been found after experimentation,

Heat Affected Zone (HAZ) is directly proportional to Laser Power (P) and Nozzle Diameter $(\phi)$ applied during the cutting operations, meaning more power and beam diameterresultsinmore heat decapitated by the laser beam to the plate and vice versa, as the heat discharged by the laser beam which is flashed out of discharge tube is dependent on power supplied and nozzle diameter of the feedback mechanism.

\section{$\mathrm{HAZ} \propto \mathrm{P}, \phi$}

Heat Affected Zone (HAZ) was inversely proportional to the laser cutting speed (V) used to move to the nozzle over the plate during the cutting operation, reason for this statement is that cutting speed indirectly controls the contact time of laser beam with the plate and hence more cutting speed decreases the heat transmissionfromlaserbeamtobrassplate.

$$
\mathrm{HAZ} \propto
$$

\section{REFERENCES}

1. Sandeep Kumar Singh Ajay Kumar Maurya "Review on Laser Beam Machining Process Parameter Optimization" published at International Journal for Innovative Research in Science \& Technology Volume 3 Issue 08 January 2017 ISSN (online): 2349-6010 (pp 34-38).

2. Mr.AmitkumarD.ShindeandProf.PravinR. Kubade "Investigation of Effect of LASER Beam Machining (LBM) process parameters on Performance Characteristics of Stainless Steel (SS 304)" published at International Journal of Engineering Research and Technology Volume 10, Number 1 (2017), (ISSN0974-3154),(pp621-625).

3. Imed Miraoui, Mohamed Boujelbene, and Mouna Zaied "High-Power Laser Cutting of Steel Plates: Heat Affected Zone Analysis" published by Hindawi Publishing Corporation in Advances in Materials Science and Engineering Volume 2016 (Article ID:1242565)

4. Archana Tamrakar and S. N. Siddique "Optimization of Hybrid Robot for LASER cutting operations" proceedings of BITCON- 2015 Innovations for National Development, National Conference on: Innovations in Mechanical Engineering for Sustainable Development, published at International Journal of Advanced Engineering Research and Studies (E-ISSN2249-8974).

5. Chithirai Pon Selvan M, Nethri Rammohan and Sachidananda HK "Laser Beam Machining: A Literature Review on Heat affected Zones, Cut Quality and Comparative Study" published at European Journal of Advances in Engineering and Technology, 2015, 2(10): (pp 70-76)Research ArticleISSN:2394 -658X by ManipalUniversity, Dubai.

6. Yogesh D. Pawar, Dr. K. H. Inamdar "Optimization of Quality Characteristics of Laser Cutting" published at Journal of Emerging Technologies and Innovative Research (JETIR) June 2015, Volume 2, Issue 6 (JETIR1506048)(pp1959-1963).

7. M, Nethri Rammohan and Sachidananda HK "Laser Beam Machining: A Literature Review on Heat affected Zones, Cut Quality and Comparative Study" published at European Journal of Advances in Engineering and Technology, 2015, 2(10): (pp 70-76) Research Article ISSN: 2394 - 658X by ManipalUniversity, Dubai.

8. Yogesh D. Pawar, Dr. K. H. Inamdar "Optimization of Quality Characteristics of Laser Cutting" published at Journal of Emerging Technologies and Innovative Research (JETIR) June 2015, Volume 2, Issue 6 